16 e 17 de agosto de 2018, centro de convenções da FCAV/UNESP - Câmpus de Jaboticabal, SP

\title{
CONTROLE ESTATÍSTICO DE PROCESSO NO MONITORAMENTO DE PERDAS NO ARRANQUIO DO AMENDOIM SUBMETIDO A DOIS PREPAROS DE SOLO
}

Francisca Nivanda de Lima Estevam'; Renata Fernandes de Queiroz ${ }^{2}$; Francisca Edcarla de Araújo Nicolau$^{3}$; Carlos Eduardo Angeli Furlani ${ }^{4}$; Elizabeth Haruna Kazama ${ }^{5}$ Jean Lucas Pereira Oliveira ${ }^{6}$

1Doutorando em Agronomia (Ciência do solo), FCAV/UNESP, Jaboticabal, SP, nivanda_lima@hotmail.com; ${ }^{2}$ Doutorando em Agronomia (Ciência do solo), FCAV/UNESP, Jaboticabal, SP; ${ }^{3}$ Doutorando em Agronomia (Ciência do solo), FCAV/UNESP, Jaboticabal, SP;4Docente da FCAV/UNESP, Jaboticabal, SP;5Doutorando em Agronomia (Produção Vegetal), FCAV/UNESP, Jaboticabal, SP;6Mestrando em Agronomia (Produção Vegetal), FCAV/UNESP, Jaboticabal, SP.

RESUMO: Em função de vários fatores o arranquio mecanizado do amendoim pode ocasionar elevados níveis de perdas. O presente estudo teve como objetivo avaliar por meio do controle estatístico de processo as perdas ocasionadas no arranquio do amendoim, em dois diferentes preparos de solo. O experimento foi conduzido em área de produção de amendoim no Município de Jaboticabal - SP, utilizou-se dois preparos de solo, um convencional e o conservacionista. O delineamento foi inteiramente casualizado adotando as premissas do controle estatístico de processo, sendo avaliados 20 pontos em cada tratamento. As cartas de controle foram uma ferramenta eficaz no monitoramento do processo de arranquio do amendoim. O preparo conservacionista foi superior ao convencional em produtividade e obteve maior resultado nas perdas invisíveis e menor nas perdas visíveis.

Palavras-Chave: Arachis hypogaea L., cartas de controle, conservação do solo.

\section{INTRODUÇÃO}

A produção de amendoim no Brasil está concentrada no Estado de São Paulo, onde a produção no período de 2011 a 2016 alcançou a média de 312 mil toneladas ao ano (IEA, 2016), sendo cultivada na maioria das vezes em sucessão na renovação de canaviais e basicamente praticada por agricultores arrendatários (BOLONHEZI et al., 2005). As perdas durante o arranquio podem ocasionar impacto na produtividade, por isso segundo CARLEY et al (2008). É preciso determinar o momento correto de início da colheita do amendoim para se atingir máxima produtividade. Por se tratar de planta com hábito de crescimento indeterminado, mesmo quando a colheita ocorre em momento ótimo, o amendoim apresenta vagens em diferentes estádios de maturação, o que pode ocasionar desprendimento das vagens no momento do arranquio, seja por problemas de compactação, entre outros.

As cartas de controle são ferramentas do controle estatístico de processo (CEP), com intuito de avaliar o processo de modo a proporcionar melhorias em sua qualidade. Segundo HENNING (2010), as cartas de controle consistem na plotagem de linhas que representam os limites de controle superior 
(UCL) e controle inferior (LCL), o alvo ou a média do processo (X) e pontos observados, que configuram a estatística relacionada à variável de interesse. $\mathrm{O}$ objetivo do trabalho foi avaliar por meio do controle estatístico de processo as perdas ocasionadas no arranquio do amendoim, em dois diferentes preparos de solo.

\section{MATERIAL E MÉTODOS}

O experimento foi desenvolvido em área de produção de amendoim no Município de Jaboticabal - SP, nas coordenadas geográficas latitude: $21^{\circ} 14^{\prime} \mathrm{S}$ e longitude: $48^{\circ} 16^{\circ} \mathrm{O}$. O solo é classificado como Latossolo Vermelho Eutroférrico Típico. A cultivar utilizada foi a IAC OL3, de ciclo curto, onde a maturação é atingida entre 125 e 130 dias. Foram utilizados dois preparos de solo, o convencional e o conservacionista utilizando o equipamento Rip Strip. O trator utilizado na operação foi o Valtra Valmet 1780 (162cv). As variáveis utilizadas para avaliar a qualidade do processo foram: perdas visíveis do arranquio (PVA), perdas invisíveis do arranquio (PIA), perdas totais do arranquio (PTA) que correspondem à soma das perdas visíveis e invisíveis, classificadas de acordo com a denominação proposta por SILVA \& MAHL (2008). As amostras foram coletadas utilizando uma armação com área amostral de $2 \mathrm{~m}^{2}(1,11 \times 1,80)$, esta medida foi referente a largura do arrancadorinvertedor utilizado. Para a determinação das perdas visíveis do amendoim realizadas após aranquio, posicionou-se a armação após a retirada da leira e então recolheu-se todas as vagens e grãos soltos que estavam sobre o solo e dentro da armação. Para a mensuração das perdas invisíveis, utilizou-se a mesma armação no mesmo local onde estava posicionada e com ajuda de um enxadão, cavou-se o solo a uma profundidade de aproximadamente $0,15 \mathrm{~m}$, onde foram coletadas as vagens restantes e as perdas totais do aranquio foram determinadas a partir do somatório das perdas visíveis e invisíveis.

Foram coletadas amostras em todos os pontos para a estimativa da produtividade média de cada ponto. As vagens coletadas em cada ponto amostral foram acondicionadas em sacos de papel, identificadas e pesadas para avaliação da produtividade. Após a secagem na estufa a $103^{\circ} \mathrm{C}$ a massa das vagens foi novamente determinada obtendo-se os valores das perdas que foram extrapolados para $\mathrm{kg} \mathrm{ha}^{-1}$, com posterior correção para $8 \%$ de teor de água. Os valores de perdas foram calculados em $\mathrm{kg}$ $h^{-1}$ e porcentagem em relação à produtividade. O programa Minitab ${ }^{\circledR}$ foi utilizado para o teste de normalidade de Anderson-Darling e o monitoramento do processo por meio de cartas de controle individual, em todas as variáveis estudadas, gerando gráficos para cada tratamento.

\section{RESULTADOS E DISCUSSÃO}

De acordo com a carta de controle para perdas visíveis (Figura 1) comparando os dois tratamentos utilizados, observamos que o preparo convencional obteve as menores perdas em relação ao tratamento conservacionista. A amplitude do rip strip em alguns pontos no decorrer do processo é maior, isso é indicativo de maior variabilidade, portanto de menor qualidade no processo. 


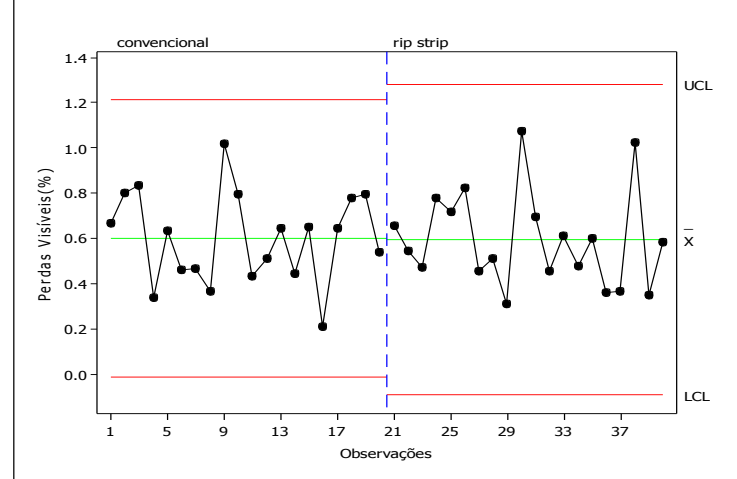

Figura 1. Carta de controle individual para perdas visíveis; $x$ : média; UCL: Limite superior de controle; LCL e LB: Limite inferior de controle.

Segundo SAMOHYL (2009), as linhas de maior amplitude indicam que o processo está sofrendo causas comuns, que é mais difícil de eliminar do que as causas especiais, que podem ocorrer durante o processo, como falhas no equipamento, operação, entre outras. Os valores encontrados de perdas visíveis para os dois tratamentos convencional e rip strip (média de 0,6\% e 0,5\%, respectivamente) estão abaixo da faixa encontrada por MAHL et al. (2009) e SANTOS et al. (2010), que encontraram perdas visíveis no intervalo de 0,7 a 14,8\% e DOS SANTOS et al., (2013) que encontraram valores de 1,6 a $4,6 \%$.

Nas cartas de controle para as perdas invisíveis do amendoim (Figura 2) houve pontos de alta variabilidade no preparo convencional e em ambos tratamentos encontramos pontos fora de controle (outliers), existe indícios fortes para a presença de causas especiais. Os valores representados na carta de controle estão abaixo da faixa encontrada por Dos Santos et al., (2013) que foi de 1,9 a 8,2\%.

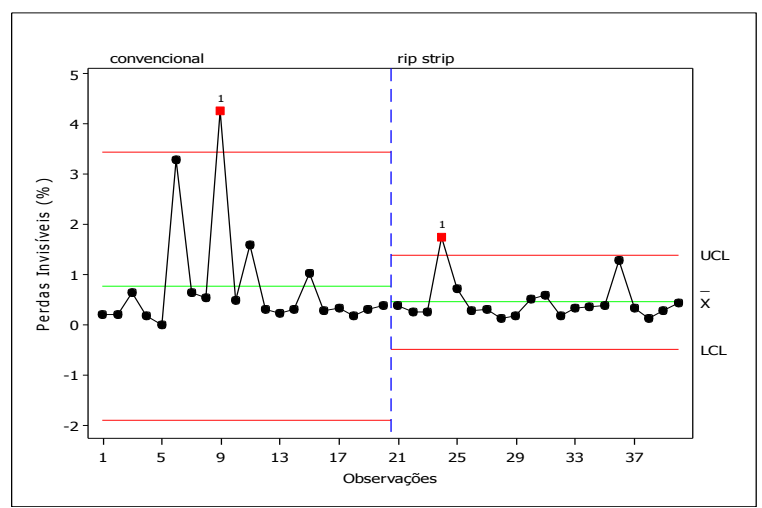

Figura 2. Carta de controle individual para perdas invisíveis; x: média; UCL: Limite superior de controle; LCL e LB: Limite inferior de controle.

As perdas invisíveis são em decorrência de alguns fatores, como falhas no processo de aranquio, solo compactado que impossibilita que o arrancador atinja a profundidade adequada para arrancar e 
inverter a planta, escassez de chuvas que influência na umidade do solo, que estando mais seco e rígido pode danificar os arrancadores na operação de arranquio provocando sua quebra e assim aumentando não só as perdas invisíveis como as visíveis.

A perdas totais (Figura 3) tiveram comportamento semelhante a carta de controle para perdas invisíveis, apresentaram valores menores do que o esperado de 5\%. Ambas apresentaram pontos mais distantes da média o que configura menor qualidade no processo e indica atuação de alguma causa especial.

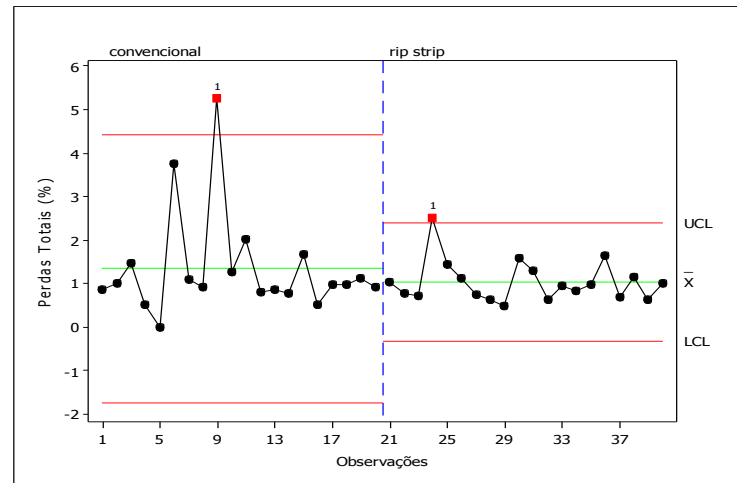

Figura 3. Carta de controle individual para perdas totais; $x$ : média; UCL: Limite superior de controle; LCL e LB: Limite inferior de controle.

Os Outliers apresentados podem ser atribuídos a fatores como embuchamento do arrancador, onde a retirada do excesso de material pode ocasionar perdas, falta de regulagem na velocidade de movimentação dos componentes do arrancador, algum erro de manobra do operador, entre outros motivos podem ter afetado no aparecimento destes pontos fora de controle.

A produtividade encontrada na área experimental (Figura 4), em ambos os tratamentos esteve abaixo da média esperada para a cultivar IAC OL3, segundo o Instituto agronômico de Campinas (IAC, 2018), onde a produtividade média é de $4.500 \mathrm{Kg} / \mathrm{ha}$, com potencial para $7.000 \mathrm{~kg} / \mathrm{ha}$. A média da produtividade do tratamento utilizando o rip strip se manteve superior em relação ao preparo convencional para este trabalho. 


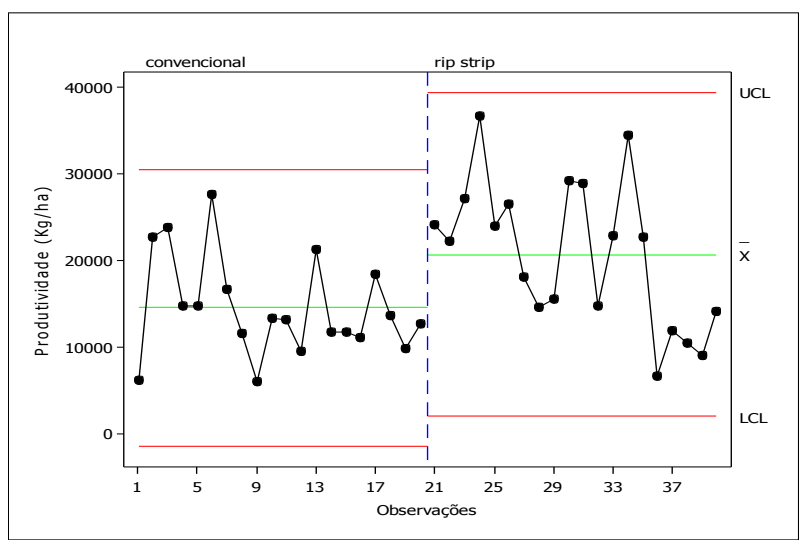

Figura 4. Carta de controle individual para produtividade; $x$ : média; UCL: Limite superior de controle; LCL e LB: Limite inferior de controle.

De acordo BOLONHEZI et al., (2007), preparos conservacionistas possibilitarão o cultivo do amendoim no sistema de plantio direto, em áreas de colheita de cana crua, reforma de pastagens e em rotação com culturas graníferas, o que proporcionará maior sustentabilidade na produção do amendoim. Outros pesquisadores relatam sobre resultados favoráveis aos sistemas conservacionistas, ou sem diferença significativa, com indicação da possibilidade de obtenção de produções comerciais com aumentos de até 10\% (HARTZOG; ADAMS, 1989; WRIGHT, 1991; GRICHAR, 1998), segundo TASSO JÚNIOR (2003), a adoção de sistemas conservacionistas resulta em aumentos significativos na produção de vagens.

\section{CONCLUSÃO}

As cartas de controle foram uma ferramenta eficaz no monitoramento do processo de arranquio do amendoim.

O preparo conservacionista foi superior ao convencional em produtividade.

As perdas visíveis foram menores no preparo convencional.

As perdas invisíveis foram superiores no preparo convencional.

\section{REFERÊNCIAS BIBLIOGRÁFICAS}

BOLONHEZI, D.; MUTTON, M. Â.; MARTINS, A. L. M. Sistemas conservacionistas de manejo do solo para amendoim cultivado em sucessão à cana crua. Pesquisa Agropecuária Brasileira, Brasília, v.42, n.7, p.939-947, jul. 2007.

BOLONHEZI, D.; SANTOS, R. C. dos; GODOY, I.J. de. Manejo cultural do amendoim. In: SANTOS, R.C. dos. (Ed.). O agronegócio do amendoim no Brasil. Campina Grande: Embrapa Algodão, 2005. p.193-244.

CARLEY, D. S. et al. Peanut Response to Planting Date and Potential of Canopy Reflectance as an Indicator of Pod Maturation. Agronomy Journal, v. 100, n. 2, p. 376-380, 2008. 
16 e 17 de agosto de 2018, centro de convenções da FCAV/UNESP - Câmpus de Jaboticabal, SP

DORNER, J. W. Relationship between kernel moisture content and water activity in different maturity stages of peanut. Peanut Science, v. 35, n. 2, p. 77-80, 2008.

DOS SANTOS, E. P., DA SILVA, R. P., BERTONHA, R. S., NORONHA, R. H., \& ZERBATO, C. Produtividade e perdas de amendoim em cinco diferentes datas de arranquio. Revista Ciência Agronômica, v. 44, n. 4, p. 695, 2013.

GRICHAR, W. J. Long term effects of three tillage systems on peanut grade, yield, and stem rot development. Peanut Science, v.25, p.59- 62, 1998.

HARTZOG, D.L.; ADAMS, J.F. Reduced tillage for peanut production. Soil \& Tillage Research, v.14, p.85-90, 1989.

HENNING, E. Aperfeiçoamento e desenvolvimento dos gráficos combinados Shewhart-CUSUM binomiais. 2010.251f. Tese (Doutorado em Engenharia de Produção) - Universidade Federal de Santa Catarina. Florianópolis, 2010.

IAC - Instituto agronômico de Campinas. Cultivares de amendoim. Disponível em:< http://www.iac.sp.gov.br/areasdepesquisa/graos/amendoim.php>. Acesso: Jul. 2018.

IEA - Instituto de Economia Agrícola. Amendoim: alta na produção e nas exportações. Análises e Indicadores do Agronegócio. 11, n. 11, novembro 2016. Disponível em: $<$ http://iea.sp.gov.br/ftpiea/AIA/AIA-68-2016.pdf>Acesso em: Jul. 2018.

MAHL, D. et al. Perdas no arranquio mecanizado do amendoim em função da velocidade de deslocamento e espaçamento entre hastes. In: Congresso Brasileiro de Engenharia Agrícola, 38., 2009, Petrolina. Anais..., Jaboticabal: SBEA, 2009. 1 CD-ROM.

SAMOHYL, R. W. Controle Estatístico de Qualidade. Elsevier: Rio de Janeiro, 2009.

SANTOS, E. P.; SILVA, R. P.; FURLANI, C. E. A.; BERTONHA, R. S.; MEDEIROS; R. S. Perdas na colheita mecanizada de amendoim. In: CONGRESO LATINOAMAERICANO Y DEL CARIBE DE INGENIERÍA AGRÍCOLA, 9., Vitório, ES. 2010. Anais..., Vitória: SBEA, 2010. 1 CD-ROM.

SILVA, R. P.; MAHL, D. Relatório do projeto de pesquisa: Perdas na colheita mecanizada do amendoim safra 2007/2008. Relatório de Pesquisa. Laboratório de Máquinas e Mecanização Agrícola - LAMMA. Jaboticabal, Nov. 2008. 47p.

TASSO JÚNIOR, L. C. Cultura de soja, milho e amendoim sob diferentes sistemas de manejo do solo em área com palha residual de colheita mecanizada de cana crua. Jaboticabal: UNESP, 2003. 157p. Dissertação Mestrado.

WRIGHT, F.S.; PORTER, D.M. Digging date and conservational tillage influence on peanut production. Peanut Science, v.18, p.72- 75, 1991. 